DOI:

Наталія Фещенко, викладач кафедри дизайну

Хортицької національної навчально-реабілітаційної академії

\title{
ВПЛИВ ІНФОРМАЦИЙНИХ ТЕХНОЛОГІЙ НА ПРОЦЕС ПРОЕКТУВАННЯ ОДЯГУ У СУЧАСНОМУ СВІТІ З ОГЛЯДОМ СУПРОВОДЖУЮЧОГО ПРОГРАМНОГО ЗАБЕЗПЕЧЕННЯ, ОГЛЯД АКТУАЛЬНИХ СИСТЕМ САПР
}

Однією з основних проблем переходу сучасної швейної промисловості від традичійних методіє планування виробництва і проектування колекцій, починаючи зі створення моделі і закінчуючи масовим пошивом, $\epsilon$ впровадження інформаційних технологій. Використання відповідного програмного забезпечення $i$ супроводжуючого обладнання представляється ключовим критерієм ефективності швейного підприємства в конкурентній боротьбі за частину ринку. Зниження часу на розробку моделі $і$ зменшення витрат матеріалу - зменшують собівартість продукиї та забезпечують додатковим часом конструкторів на творчу складову в створенні одягу.

Ринок програмного забезпечення, щуо стрімко розвивається, пропонує широкий спектр систем автоматизованого проектування САПР одягу, і швейному підприємству здійснити правильний вибір, часом, непросто. Приймаючи рішення необхідно врахувати ряд факторів, найважливішими з яких є вартість $i$ фуниіональність

У статті автор висвітлив основні популярні системи САПР та зробив їх порівняльний аналіз.

Ключові слова: САПР одягу; дизайн; програмні модулі; розкладка, градачія лекал; конструювання; моделювання.

Табл. 1. Лім. 9.

Nataliya Feshchenko, Lecturer of the Clothing Design Department Khortytsya National Rehabilitation Academy

\section{THE INFLUENCE OF INFORMATION TECHNOLOGIES ON THE PROCESS OF DESIGN OF CLOTHING IN THE MODERN WORLD WITH THE OVERVIEW OF ACTUAL CAD SYSTEMS}

One of the main problems of transition of the modern garment industry from the traditional methods of production planning and collection design, from the creation of the model to the mass tailoring, is the introduction of information technology.

The creative component of the designer's work is based on the ideas of famous representatives of the fashion world. It is almost impossible to invent a novelty worthy of attention from scratch. Creating new ideas in any field is based on a vast knowledge of the material accumulated in the past, its analysis and careful study. Right here is the detailed systematization of various fashion trends, implemented by some systems CAD clothing, can significantly speed up and facilitate the work of designers and constructors. Also, the application of CAD gives good results in the presence of a ready design solution, such as the development of patterns.

The use of appropriate software and accompanying equipment is a key criterion for the efficiency of the garment company in the competition for part of the market. Reducing the time to develop a model and reducing the cost of material - reduce the costand production and provide additional time for designers creative part in creating clothes.

The rapidly evolving software market offers a wide range of CAD design systems for clothing. The developers offer both initial, application systems that serve as a practical help in individual activities, such as housewives, and powerful complexes of clothing and material support for large enterprises, providing the ability to adjust to the regional market characteristics and take into account the characteristics of the enterprise. Such systems are quite functional and good, but usually not cheap.

As a consequence, making the right choice is sometimes difficult. When deciding to consider a number of factors, the most important of which are cost and functionality.

In the article the author has covered the main popular CAD systems and made their comparative analysis.

Keywords: CAD systems; design; software modules; layout; gradation of patterns; modeling.

$2{ }^{2}$ агальна постановка проблеми. Для того, цоб залишатися конкурентоспроможним в епохуінформаційних технологій, необхіднойти в ногу з часом. Це стосується всіх галузей життя, включаючи й швейне виробництво. I хоча сфера штучного інтелекту не знайшла поки застосування безпосередньо у виготовленні одягу, але в інструментах розробки і створення ідеї моделі 
цілком може бути використана. Без комплексного підходу до питань інформаційних технологій в швейної галузі, включаючи як виробництво так і навчання фахівців поводженню $з$ передовими системами автоматизованого проектування (далі САПР), не може обійтися жоден нормальний вуз. У статті розглянуті провідні західні та вітчизняні САПР і проведено їх порівняльний аналіз.

Формування мети статті. Огляд існуючих САПР одягу для швейного виробництва та їх порівняльний аналіз.

Виклад основного матеріалу. Застосування САПР дозволяє збільшити продуктивність праці на швейному виробництві більш, ніж у декілька разів: значно знизити час розробки моделі одягу конструктором (на думку автора це головна перевага!) та скоротити витрати матеріалів. Головні етапи підготовки швейних виробів включають побудову базових конструкцій, конструктивне моделювання, розробку лекал по розмірам, розкладку та розташування лекал на плотері.

Системи САПР запропоновані розробниками на ринку програмних продуктів можна розділити, змістовно, на дві категорії - перші, більш орієнтовані на індивідуальну, творчу складову, створення нових моделей, підбір і візуалізацію різних матеріалів виготовлення одягу, як правило, не дуже дорогі для придбання (ціна коливається від 50 до 500 дол.), і другі - повноцінні, потужні інструменти, для проектування моделей та математично найменш витратного (пропонується кілька варіантів) розкрою матеріалів - розкладки лекал для порізки на плоттері, або в ручному режимі.

Останні, здебільше, мають відповідні плагіни для обміну даними між різними системами САПР, та конвертування готового макету у зручні файли.

Узагальнимо основні групи робочих модулів САПР і коротко опишемо їх, оскільки вони схожі між собою, ми не будемо детально зупинятися на їх описі для кожної конкретної САПР.

Наведемо основні типи робочих модулів:

1. Модулі, що дозволяють робити параметричне конструювання лекал. (тобто внесенням розмірів числовим способом).

2. Модулі для графічного (в ручному режимі) проектування лекал.

3. Модулі для автоматичного перестроювання лекал при зміні розміру і надбавок.

4. Модулі для оформлення та градації лекал

5. Модулі системи управління даними що забезпечують експорт лекал в інші САПР.

6. Модулі оптимізації використання тканини для мінімізації кінцевих залишків.
7. Модулі для задання оптимального розкрою на плоттері, та самого розкрою.

Автор не мав можливості протестувати всі запропоновані ринком САПР, оскільки кожна з них $\epsilon$ досить дорогим продуктом, що вимагає, як значних фінансових витрат, так і додаткових навичок володіння особливостями розробки в кожній окремій програмі.

Крім того, аналіз, що проводився деякими дослідниками $[1,83]$ на предмет порівняння витрат часу на створення моделей, лекал і розкладок, автор вважає сумнівними, з огляду на конкретні індивідуальні навички користувача володінням кожної з програм, тобто, дослідження носить скоріше суб'єктивний характер, що залежить від конкретної людини.

Займатися ж дослідженням швидкості навчання тою чи іншою САПР системою, автор вважає недоцільним, тому що це виходять за рамки швейних дисциплін, та більш стосується питань здатності до навчання та психології.

Отже перейдемо до розгляду конкретних систем САПР та їх особливостей.

\section{САПР "Комтенс"}

САПР "Комтенс" - одна 3 найбільш поширених систем САПР на пострадянських теренах. Програмне забезпечення дає можливість автоматизувати проектування моделей, пристосовуючись до окремих умов виробництва. [2].

Вибір задіяних дизайнером модулів залежить від кількості продукції, що випускається. САПР "Комтенс" пропонує різні варіанти проектування моделей: можна використовувати як графічні, де зміни в лекала вносяться вручну модифікацією геометричної форми деталей, так і параметричні - внесенням розмірів числовим способом.

Типові версії програмного забеспечення САПР "Комтенс":

1. Индив - версія, орієнтована для використання індивідуальними підприємцями, що здійснюють розробку та градацію лекал. Версія адаптована до умов використання вузьких плотерів і принтерів для отримання лекал виробів.

2. Ательє-версія, призначена для використання в ательє і дизайн-студіях, що розробляють моделі виробів одягу та здійснюють градацію лекал. У даній.

3. Версії доступні всі можливості з побудови базових лекал, конструюванню, моделюванню та градації лекал.

4. Підприємство - найбільш затребуване рішення для малих i середніх швейних підприємств, що використовують традиційний (ручний) метод розкрою. Поряд 3 


\section{ВПЛИВ ІНФОРМАЦЙНИХ ТЕХНОЛОГІЙ НА ПРОЦЕС ПРОЕКТУВАННЯ ОДЯГУ У СУЧАСНОМУ СВІТІ З ОГЛЯДОМ СУПРОВОДЖУЮЧОГО ПРОГРАМНОГО ЗАБЕЗПЕЧЕННЯ, ОГЛЯД АКТУАЛЬНИХ СИСТЕМ САПР}

конструюванням, моделюванням і градацією лекал, версія має розширені можливості 3 проектування розкладок лекал з урахуванням умов конкретного розкрійного виробництва.

\section{САПР Gemini}

Від румунської компанії Gemini Cad Systems що з'явилася у 2003 році.

Як і попередня программа, САПР Gemini розрахована на графічний та параметричний спосіб проектування моделей та внесення змін до готових лекал в залежності від розмірів та особливостей фігури [3].

CAПP Gemini складається з чотирьох окремих програм:

1. Програма Photo Digitizer призначена для оцифровки лекал, розроблених на папері. Використовуючи фотоапарат, можна переносити паперові лекала на цифровий носій, коригувати їх, додаючи нові елементи в модель.

2. Редактор Gemini Pattern Editor-конструкторський блок для роботи з лекалами. Дозволяє будувати викрійки будь-якої складності, автоматично виконує градацію за розмірами ростових груп. Дизайнер завдає конструкторські та модельні лінії, об'єднує деталі, редагує зрізи, розподіляє виточки та створює складки і зборки.

3. Програма Gemini Cut Plan використовується для розкладки по тканині з урахуванням ширини рулону, кількості виробів, розмірної сітки. Можна отримати розрахунок витрат, обчислити кількість тканини для виробництва партії швейних виробів.

4. Програма створення розкладок Gemini NestExpert автоматично оптимізує розкладки, щоб скоротити витрати тканини. Можлива ручна та комбінована розкладка.

\section{CAПP Grafis}

САПР Grafis від німецької фірми Grafis Software Dr.K.Friedrich GbR містить не тільки програми по конструюванню одягу, але на додаток професійні плагіни для імпорту та експорту інтерфейсу.

Основні програми [4] (опис взято з офіційного сайту виробника на англ.):

1. CutterControl - для контролю над одним або декількома шарами тканини для точного i безвідходного виробництва.

2. Autonester - автоматично створює схему розкрою.

3. Cut order planning - організовує план розкрою і різання на шматки.

4. Vstitcher - прискорювач різноманітних шляхів генерації 3 д моделей.

5. ProfileFitPatternSuite - призначена для обміру людини, використовуючи дві цифрові фотографії.
6. ProfileFitPatternPhoto -оцифровування шаблонів на екрані без дігітайзера.

7. Pattern on Demand ${ }^{\circledR}$ - повна автоматизація виготовлення, від обміру до постановки на виробництво.

\section{САПР Грація}

Основні комплекти програм:

1. Комплект для підприємств - забезпечує організацію масового виробництва жіночого, чоловічого, дитячого одягу, трикотажних i хутрових виробів, спеціального і форменого одягу, шкільної форми, головних уборів, шкіргалантереї, туристського спорядження [5].

2. Комплект для ательє - підвищує ефективність роботи ательє, малих підприємств і конструкторських бюро при розробці всіх видів одягу, головних уборів, шкіргалантереї, туристського спорядження.

3. Комплект для фрилансеров - надає широкі можливості для проектування промислових лекал одягу та ефективної взаємодії зі швейними підприємствами.

4. Комплект для любителів шиття - дозволяє освоїти високу комп'ютерну технологію проектування швейних виробів САПР “ГРАЦІЯ” і використовувати в особистих цілях для побудови лекал всіх видів одягу.

5. Комплект для Студентів - призначений для використання в навчальному процесі за спеціальностями "Конструювання і моделювання" та “Технологія виготовлення” швейних виробів.

\section{CAIP JULIVI}

Київська Компанія САПРЛЕГПРОМ, провідний розробник програмного забезпечення для конструювання одягу та управління швейним виробництвом з 1980-х років.

Розробник пропонує 2 комплекти програм окремо, або одну повну, що складається 3 двох, за меншу плату [6].

1. Конструктор - дозволяє робити конструювання одягу від базової або типової конструкції до запуску у виробництво: побудова базової конструкції, розмноження лекал, моделювання, побудова похідних лекал (підкладки, клейових прокладок і т.п.). Крім роботи 3 текстильними матеріалами програми адаптовані для конструювання виробів 3 трикотажу та шкіри.

Комплект "Конструктор" застосовують для:

- Використання каталогу базових основ за методиками побудови (Мюллер, ємко РЕВ, ЦНІІШП, ЦОТШЛ, Янчевський, Кудряшову, Гріншпану і т.п.).

- Перевірки і модифікації лекал, побудови похідних лекал з їх автоматичним перестроюванням слідом за змінами основних лекал. 


\section{ВПЛИВ ІНФОРМАЦЙНИХ ТЕХНОЛОГІЙ НА ПРОЦЕС ПРОЕКТУВАННЯ ОДЯГУ У СУЧАСНОМУ СВІТІ З ОГЛЯДОМ СУПРОВОДЖУЮЧОГО ПРОГРАМНОГОЗАБЕЗПЕЧЕННЯ, ОГЛЯД АКТУАЛЬНИХ СИСТЕМ САПР}

\begin{abstract}
- Формування специфікації за розмірними базами даних по ДСТУ.

- Моделювання, паралельного і конічного розширення, створення, перенесення та закриття виточок, розрізання лекал, відрізання та склеювання.

- Технічного та параметричного (по розмірним баз даних) розмноження лекал

2. Розкладчики лекал - програма, що оснащена набором функціональних можливостей, необхідних для виконання розкладок лекал в ручному, автоматичному і напівавтоматичному режимі. Має зручний інтерфейс, що дозволяє враховувати всі варіанти настилання і технології крою. Програма враховує особливості тканини (гладка, смужка, клітина, є можливість задати рапорт, браковані ділянки) та зазор між лекалами.
\end{abstract}

\section{CAПР ASSYST}

Програмне рішення німецької компанії ASSYST GmbH (Німеччина) для виробників одягу.

Конструкторська програма CAD.ASSYST складається $з$ таких модулів:

Smart.Filter - дозволяє створювати кілька варіантів одного лекала.

Smart.Texture - для реалістичного зображення лекал в кольорі і текстурі.

Smart.Guide - містить опції по модифікації і спрощення створення лекал, а також бібліотеку по базах “Мюллер і син”.

Розкладчик лекал LAY.ASSYST [7] програма для ефективної розкладки лекал в ручному, напівавтоматичному і автоматичному режимах. Розкладчик дозволяє враховувати велику кількість різних параметрів, що характеризують особливості виробництва, в тому числі методи настилу, особливості текстури і принта матеріалів, технологію крою та ін.

Розкладчик включає можливість завантаження лекал. За необхідності, можна виключити окремі деталі або цілі групи деталей $з$ процедури розкладки. Після цього всі деталі можна розмістити безпосередньо в LAY.ASSYST або ж відправити в веб-сервіс automarker.com для автоматичного формування розкладок. Можна комбінувати окремі деталі і об’єднувати їх в групи, попередньо позиціонуючи їх.

Програма AUTOCOST для попередньої калькуляції витрат матеріалів. Результатом розрахунків AUTOCOST є актуальні розкладки, точний розрахунок вартості матеріалів, часу і плану роботи розкрійного цеху.

\section{САПР Crea Solution}

САПР Crea Solution від італійських розробників.

VStitcher - інструмент, що дозволяє відмовитися від створення прототипу моделі і отримати реалістичну посадку кожного предмета одягу. Тиск на шкіру, натяг і еластичність тканини моделюються в реалістичній манері. Існує широкий вибір налаштування манекенів, доступних в більш ніж 20 позах і параметрах.

Lotta - це 3D рішення, спеціально розроблене для створення одягу або цілої колекції [8]. Можна отримати доступ до бібліотеки базових шаблонів, персоналізувати їх з різними розрізами, тканинами i деталями. Програма інтегрується 3 Adobe Illustrator (практично єдиний варіант САПР інтегрований 3 популярними графічними редакторами), що вигідно відрізняє його від інших і дозволяє завантажувати необхідне забарвлення, щоб отримати набір текстур для кожної моделі.

\section{САПР САМЕО}

Розробник - американська компанія Wild Ginger Software, яка спеціалізується на розробці програмного забезпечення та супутніх товарів для дизайну одягу, любителів шиття і рукоділля, а також для викладачів і студентів з області дизайну моди та театрального костюма [9].

Програма для професійного дизайну САМЕО складається $з$ трьох блоків, які включать в себе можливості побудови, моделювання та градації лекал:

1. Pattern Design містить інструменти, необхідні для створення виробничих моделей. Включені інструменти малювання 2D.

2. Grading представляє три методи для зняття мірок фігури. Інструменти CAMEO Coordinate, Measurement ra Point Grading.

3. Made to Fit надає можливість змінювати стилізовані візерунки для будь-якої частини моделі, а також дозволяє створювати шаблони і автоматично змінювати їх розмір, але для цього потрібний модуль Pattern Design.

На додаток до Сатео розробники пропонують придбати набори викрійок жіночого, чоловічого, дитячого одягу, трикотажу та білизни.

\section{Порівняльний аналіз САПР}

Двома ключовими критеріями в порівняльному аналізі розглянутих систем САПР $\epsilon$ їх функціональність та вартість.Власне вартість каже сама за себе, а функціональність визначається кількісно і залежить від величини підприємства, персонал якого САПР може забезпечити безперебійною роботою. Таким чином, ефективність САПР системи відображена співвідношенням цих двох показників. Кількісно 


\section{ВПЛИВ ІНФОРМАЦЙНИХ ТЕХНОЛОГЙ НА ПРОЦЕС ПРОЕКТУВАННЯ ОДЯГУ У СУЧАСНОМУ СВІТІ З ОГЛЯДОМ СУПРОВОДЖУЮЧОГО ПРОГРАМНОГО ЗАБЕЗПЕЧЕННЯ, ОГЛЯД АКТУАЛЬНИХ СИСТЕМ САПР}

Таблиця 1.

Порівняльна таблиця САПР систем

\begin{tabular}{|c|c|c|c|c|c|c|}
\hline \multirow[t]{2}{*}{ Найменування } & \multirow{2}{*}{$\begin{array}{l}\text { Офіційний сайт виробника } \\
\text { або регіонального дилера }\end{array}$} & \multirow{2}{*}{$\begin{array}{c}\text { Країна } \\
\text { виробництва }\end{array}$} & \multirow[t]{2}{*}{ Вартість } & \multicolumn{3}{|c|}{ Призначення для бізнесу } \\
\hline & & & & малий & середній & великий \\
\hline САПР Комтенс & http://www.comtense.ru & $\mathrm{P} \Phi$ & 5000 долл. & + & + & - \\
\hline САПР Gemini & https://www.geminicad.com & Румунія & $\begin{array}{c}\text { від } 4500 \text { до } 6000 \\
\text { долл. }\end{array}$ & + & + & + \\
\hline САПР Grafis & https://www.grafis.com/home & Німеччина & $\begin{array}{c}2900 \text { долл. але } \\
\text { тільки німецька } \\
\text { версія для } \\
\text { розповсюджен- } \\
\text { ня у Німеччині }\end{array}$ & + & + & + \\
\hline САПР Грация & http://www.saprgrazia.com & $\mathrm{P} \Phi$ & $\begin{array}{c}\text { ціна варіюється } \\
\text { від } 75 \text { долл. для } \\
\text { студентів до } \\
1400 \text { долл. для } \\
\text { великих } \\
\text { підприємств в } \\
\text { рік }\end{array}$ & + & + & - \\
\hline САПР Julivi & https://julivi.com & $\begin{array}{c}\text { Україна } \\
\text { компанія } \\
\text { САПР } \\
\text { ЛЕГПРОМ }\end{array}$ & $\begin{array}{c}\text { модуль } \\
\text { “конструктор" } \\
1750 \text { евро модуль } \\
\text { "розкладальник” } \\
950 \text { евро обидва } \\
\text { модуля разом } 2250 \\
\text { евро }\end{array}$ & + & + & + \\
\hline $\begin{array}{c}\text { САПР } \\
\text { PatternViewer }\end{array}$ & $\frac{\text { http://www.pcstitch.com/Patter }}{\underline{\text { nViewer/PatView.aspx }}}$ & США & $\begin{array}{c}\text { умовно } \\
\text { безкоштовна, } \\
\text { повна версія } \\
\text { коштує } 50 \text { долл. }\end{array}$ & + & - & - \\
\hline САПР Assyst & $\frac{\underline{\text { https://www.assyst.de/en/prod }}}{\underline{\text { ucts/cad/index.html }}}$ & Німеччина & 4000 долл. & + & + & + \\
\hline $\begin{array}{l}\text { САПР crea } \\
\text { solution }\end{array}$ & https://www.creasolution.it/ & Італія & 5000 евро & + & + & + \\
\hline САПР Cameo & $\frac{\text { http://www.wildginger.com/pr }}{\text { oducts/cameo.htm }}$ & США & 950 долл. & + & - & - \\
\hline
\end{tabular}

швейні підприємства можна розділити на три категорії: Малі підприємства - до 50 осіб, середні підприємства - до 200 осіб та великі підприємства - понад 200 осіб. Результати порівняльного аналізу відображені в таблиці 1 .

Висновок. В даний час на ринку присутні найрізноманітніші сучасні САПР системи, які відрізняються між собою як по функціональності, так і за вартістю. Вибрати відповідну систему автоматизованого проектування серед багатьох - непросте завдання. При ухваленні рішення необхідно орієнтуватися на потреби підприємства, завдання, які стоять перед користувачем, вартість придбання, утримання системи і багато інших чинників. В цілому ринок запропонованих програм САПР можна розділити за територіальним критерієм на американський, західноєвропейський і вітчизняний. Якість безпосередньо залежить від затребуваності і рівня конкуренції, а отже найбільш високий рівень конкуренції, та відповідно і якості САПР спостерігається в західноєвропейському регіоні, але і рівень цін тут найвищий. Натомість розробники пропонують технічний супровід $\mathrm{i}$ консультації, а також всілякі безкоштовні навчальні курси, семінари та практикуми. Порівнюючи програму САПР організація повинна розуміти, що прогрес не стоїть на місці, і координальних відмінностей між різними САПР подекуди важко знайти. Особливо це стосується розробки програмного забезпечення, оскільки вона не вимагає капітальних вкладень в основні засоби виробництва. Потрібно згадати, що методи проектування розглянутих САПР, повторюють методи креслення відомих векторних редакторів, які використовують вузлову підгонку ліній, мова йде, наприклад, про серію CorelDraw, тобто процес розрекламованої “унікальної методики проектування”, на якій наполягають розробники САПР, подекуди перебільшений. Програми множаться і копіюють функціонал один одного.

Тому, на суб'єктивний погляд автора статті, 


\section{ВПЛИВ ІНФОРМАЦЙНИХ ТЕХНОЛОГІЙ НА ПРОЦЕС ПРОЕКТУВАННЯ ОДЯГУ У СУЧАСНОМУ СВІТІ З ОГЛЯДОМ СУПРОВОДЖУЮЧОГО ПРОГРАМНОГОЗАБЕЗПЕЧЕННЯ, ОГЛЯД АКТУАЛЬНИХ СИСТЕМСАПР}

вибір вітчизняних розробників, є оптимальним, по співвідношенню ціна - якість.

\section{ЛIТЕРАТУРА}

1. Л.В. Кочесова. Порівняльний аналіз принципів розробки модельних конструкцій в різних САПР одягу: науковий журнал. Технікотехнологічні проблеми сервісу. №1 (11). Санкт Петербург, 2010 року. С. $80-84$.

2. САПР для швейної промисловості Комтенс. URL: http:// www.comtense.ru/soft/soft.php?page=1 (дата звернення: 07.01.2020)

3. Gemini Cad Systems URL: https:// www.geminicad.com/fashion-apparel-cad/ (last assecced: 07.01.2020)

4. Grafis Cad Software URL: https:// www.grafis.com/files/Downloads /Infomaterial/ Prospekt\%20V12_EN_web.pdf (last assecced: 07.01.2020)

5. САПР Грація URL: http://www.saprgrazia.com/ kits.php (дата звернення: 07.01.2020)

6. Cad Systems Julivi URL: https://julivi.com/ru/ prods124.html (last assecced: 07.01.2020)

7. Assyst GmbH Cad System URL: https:// www.assyst.de/en/ products/cad/index.html (last assecced: 08.01.2020)

8. CreaSolution Cad System URL: https:// www.creasolution.it/en/products/design/3d-cad/ (last assecced: 08.01.2020)

9. Wild Ginger Software. Fashion Design and Sewing Pattern Software http://www.wildginger.com/ products/cameo.htm (last assecced: 08.01.2020)

\section{REFERENCES}

1. Kochesova, L.V. (2010). Porivnialnyi analiz pryntsypiv rozrobky modelnykh konstruktsii v riznykh SAPR odiahu: naukovyi zhurnal [A comparative analysis of the principles of the development of model designs in various CAD clothing]. Technical and technological problems of service. No. 1 (11). St. Petersburg. pp. $80-84$. [in Ukrainian].

2. SAPR dlja shveinoj promislovosti Komtens [CAD for fashion industry Comtens]. Available at: http:// www.comtense.ru/soft/soft.php? page=1 (assecced 07 Jan. 2020). [in Ukrainian].

3. Gemini Cad Systems. Available at: https:// www.geminicad.com/fashion-apparel-cad/ (assecced 07 Jan. 2020).

4. Grafis Cad Software Available at: https:// www.grafis.com/files/Downloads/Infomaterial/ Prospekt\%20V12_EN_web.pdf(assecced 07 Jan. 2020).

5. SAPR Gracia [CAD Grace]. Available at: http:// www.saprgrazia.com/kits.php (assecced 08 Jan. 2020).

6. Cad Systems Julivi. Available at: https:// julivi.com/ru/prods124.html (assecced 07 Jan. 2020).

7. Assyst GmbH Cad System. Available at: https:/ /www.assyst.de/en/products/cad/index.html (assecced 08 Jan. 2020).

8. CreaSolution Cad System. Available at: https:/ /www.creasolution.it/en /products/design/3d-cad/ (assecced 08 Jan. 2020).

9. Wild Ginger Software. Fashion Design and Sewing Pattern Software Available at: http:// www.wildginger.com/products/cameo.htm (assecced 08 Jan.2020).

Стаття надійшла до редакції 08.01.2020

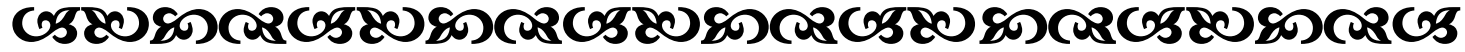

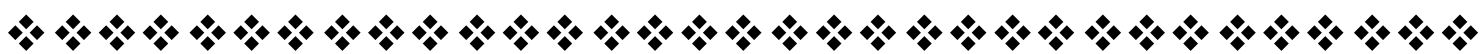

"Майбутне повинно бути зақладене в сьогоденні. ㄱe називається планом. Без нъого нішо у світі не може бути гарним”.

$$
\begin{array}{r}
\text { Теоре Крістоф Ліхтенберг } \\
\text { німецький вчений }
\end{array}
$$

"Навчайтеся й, коли прийде час, прикладати засвоєне до справи - хіба ие не преқрасно!".

$$
\begin{array}{r}
\text { Конфучій } \\
\text { давньокитайський боілософб }
\end{array}
$$

"Навряд чи взагалі є щось гідніше, яквдосконалювати свій дух, увічнювати себе в свойх творіннях $і$ дарувати їх нащадқам".

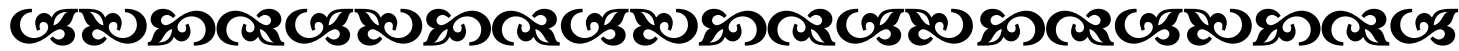

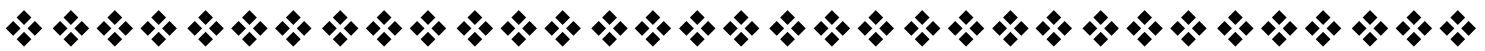

